\title{
Herpes Simplex Virus Type 1 in the Brain, Apolipoprotein E Genotype and Alzheimer's Disease
}

\author{
Uwe Beffert $^{\dagger}$, B.Sc., Philippe Bertrand ${ }^{\S}$, Ph.D., Danielle Champagne ${ }^{\dagger}$, M.Sc., \\ Serge Gauthier ${ }^{\ddagger}$ M.D., F.R.C.P.(C.) and Judes Poirier ${ }^{*}+$ Ph.D.
}

\begin{abstract}
The $\varepsilon 4$ allele of apolipoprotein $\mathrm{E}$ (apoE) is an important risk factor for Alzheimer's disease (AD), however, it is not required nor sufficient to cause the disease on its own. Herpes viruses cause acute and chronic diseases of the central nervous system and have been implicated in AD. Using a sensitive polymerase chain reaction method, latent herpes simplex virus type 1 (HSV-1) has been detected from five different brain regions (hippocampus, frontal cortex, occipital cortex, cerebellum and striatum) of neuropathologically confirmed AD and control tissue. HSV-1 positivity was then correlated with $\mathrm{AD}$, presence of the virus in specific brain regions, and apoE genotype. The results confirm that the $\varepsilon 4$ allele of apoE is a risk factor for $\mathrm{AD}$, while $\mathrm{HSV}-1$ alone is not. This held true for all five brain regions examined. Furthermore, no synergy between the two factors could be found when any one of the brain regions was examined individually or when the data were pooled. These findings emphasize that the $\varepsilon 4$ allele of apoE is a risk factor for $\mathrm{AD}$ and that HSV-1, either alone or in combination with apoE, does not represent an increased risk for AD. Furthermore, no particular brain region seems to be more infected with $\mathrm{HSV}-1$ than another, even in those regions most affected in AD.
\end{abstract}

\section{INTRODUCTION}

Herpes simplex is an infection caused by a herpes simplex virus that has an affinity for the skin and nervous system and usually produces small, transient, fluid-filled blisters on the skin and mucous membranes. Herpes simplex virus type 1 (HSV-1) infections tend to occur in the facial area, while HSV-2 infections are usually limited to the genital region. The herpes virus remains dormant in the peripheral nervous system, particularly in the trigeminal ganglia, until reactivated

* To whom correspondence should be addressed.

$\dagger$ Douglas Hospital Research Centre, McGill University, 6875 Blvd. LaSalle, Verdun, Quebec, Canada, H4H 1R3

$\S$ Centre du Medicament, Université H. Poincaré Nancy 1, 30 rue Lionnois, 54000 Nancy, France

† McGill Centre for Studies in Aging, McGill University, 6825 Blvd. LaSalle, Verdun, Quebec, Canada, H4H 1R3 by factors such as stress or exposure to ultraviolet light. The latency of herpes viruses inside neurons has raised the hypothesis that common herpetic lesions (cold sores) are likely to result in permanent establishment of HSV-1 in the central nervous system (CNS) (1). The virus is able to establish latency in several brain areas including the brainstem, basal forebrain, hippocampus, amygdala and temporal lobe (1).

Interestingly, the brain regions which have been reported to be most susceptible to HSV-1 latency are also those in which the characteristic neuropathological lesions of Alzheimer's disease (AD) are found (1). Together, these observations suggest that HSV-1 may be a potential determinant in the etiology of AD. To address this issue, researchers have examined antibody levels from serum or cerebrospinal fluid and revealed that AD or demented individuals had higher HSV-1 titres when 
compared to age-matched controls (2). However, in order to determine latent levels of HSV-1 in brain, the preferred method is now polymerase chain reaction (PCR), with a reported sensitivity of five to seven molecules of HSV-1 DNA $(3,4)$. Using PCR, Bertrand et al. demonstrated that more than $70 \%$ of all elderly brains contained HSV-1 in at least one brain area, although no difference was found between control and AD patients (5).

Most cases of AD have an age of onset after 60 years, and prevalence doubles every five years between the ages of 65 and 85 (6). The major susceptibility gene during this period of highest risk is the $\varepsilon 4$ allele of apolipoprotein $\mathrm{E}$ (apoE), accounting for as much as $50 \%$ of all attributable sporadic AD cases (7). ApoE is a polymorphic protein with three major isoforms in the human population: E2, E3 and E4, from corresponding genetic alleles $\varepsilon 2, \varepsilon 3$ and $\varepsilon 4$, respectively. The frequency of each of these alleles in the normal Caucasian population is about $8 \%, 78 \%$ and $14 \%$, for $\varepsilon 2, \varepsilon 3$ and $\varepsilon 4$ respectively (8). In both sporadic and familial late-onset $\mathrm{AD}$, the prevalence of the $\varepsilon 4$ allele is increased from $14 \%$ to approximately $37 \%$ (9-12).

Proposed roles for apoE in the brain, which may explain the isoform-specific association with $\mathrm{AD}$, include: (i) the ability to regulate neurite outgrowth (13-15); (ii) direct interactions with another $\mathrm{AD}$ associated protein, the $\beta$-amyloid peptide $(11,16-19)$; (iii) binding to tau protein, possibly slowing the initial rate of tau phosphorylation $(20,21)$; and (iv) evidence that links apoE to cholinergic impairment in $\mathrm{AD}$ (22-24).

Although the $\varepsilon 4$ allele is an important risk factor for $\mathrm{AD}$, in contrast to many genetic diseases, the risk of developing $\mathrm{AD}$ by homozygous $\varepsilon 4$ individuals is not $100 \%$ (25). Not all $\varepsilon 4$ homozygotes will develop AD by age 85 , and in some studies a small number of individuals remain free of symptoms into their tenth decade $(26,27)$. Therefore, other genetic or nongenetic factors must modify the relative risk associated with possessing an apoE $\varepsilon 4$ allele and developing AD.

Recently, Itzhaki and colleagues proposed that the combination of HSV-1 in brain and the presence of the $\varepsilon 4$ allele of apoE together confer an even greater risk for AD than either factor alone (28). The current authors' laboratory subsequently reported that in a large study of eastern Canadians, HSV-1 in brain did not contribute to greater risk for $\mathrm{AD}$ when combined with the $\varepsilon 4$ allele of apoE (29). These studies have provided the foundation for larger and more detailed studies to clarify whether HSV-1 is indeed a synergistic risk factor for AD when combined with apoE $\varepsilon 4$.

In the current study, the relationship between HSV-1 in brain and Alzheimer's disease is studied in-depth by examining the presence of HSV-1 DNA, using a PCR based method, in five different brain regions and then subdividing the cases by apoE genotype. Therefore, the objectives of this study were: (i) to determine the relative frequency of HSV-1 DNA in the CNS of control and AD individuals; (ii) to determine whether the presence of the virus correlates with those regions of brain which are predominantly affected by $\mathrm{AD}$ pathology; (iii) to determine if a synergy exists between the $\varepsilon 4$ allele of apoE and presence of HSV-1 for relative risk of $\mathrm{AD}$; and (iv) to determine if any such synergy correlates with the presence of the virus in various brain regions affected by $\mathrm{AD}$ pathology.

\section{MATERIALS AND METHODS}

Using brain tissue from the Douglas Hospital Research Centre Brain Bank (DHRC-BB; Verdun, Quebec, Canada), the brains from 74 elderly individuals (34 men, mean age 77.2 [range 53 to 93] years) and 36 without AD (27 men, mean age 72.2 [range 43 to 95 ] years) with neuropathologically confirmed AD (based on criteria established by Khatchaturian (30)), were investigated. Brains were donated voluntarily from patients previously diagnosed with probable $\mathrm{AD}$, as well as from neurologically normal individuals. The catchment area of the DHRC-BB includes western Quebec and eastern Ontario (Canada). Formalin-fixed brains were dissected to provide tissue from five CNS areas: the hippocampus, frontal cortex, occipital cortex, cerebellum and striatum. As a positive control, tissue was obtained from a temporal lobectomy of a patient suffering from clinically diagnosed herpes simplex encephalitis.

The procedure used to determine the presence of HSV-1 DNA was essentially the same as that of Bertrand et al. (5). Briefly, DNA was extracted by mincing brain tissue and then digesting in TEN9 (50 mM TRIS pH 9.0, 100 mM EDTA pH 8.0, $200 \mathrm{mM}$ $\mathrm{NaCl}$ ) containing $1 \%$ SDS and $500 \mu \mathrm{g} / \mathrm{ml}$ proteinase $\mathrm{K}$ (Boehringer Mannheim, Laval, QC). Samples were phenol-chloroform extracted twice and then once with chloroform. The DNA was then precipitated with ammonium acetate and ethanol. After incubation at $20^{\circ} \mathrm{C}$, the DNA was recovered by centrifugation at 6000 $g$ for 20 minutes. The pellet was resuspended in $100 \mu \mathrm{l}$ TE (10 mM TRIS, $1 \mathrm{mM}$ EDTA pH 8.0). PCR was performed using primers to amplify 138 bp of the HSV-1 glycoprotein D gene (5' primer: CCATACCGACCACACCGACGA; 3' primer: GGTAGTTGGTCGTTCGCGCTG) (31). Typically, 2 to $3 \mu \mathrm{g}$ of genomic DNA was used as a template in 50 $\mu 1$ reactions in PCR buffer containing 2 units Taq DNA polymerase (Promega, Madison, WI), $200 \mu \mathrm{M}$ deoxyribonucleotides, and $25 \mathrm{pmol}$ primers $\left({ }^{32} \mathrm{P} 5\right.$ '-end radiolabeled primers diluted $1 / 25$ to $1 / 50$ with cold primers). Amplification was carried out as follows: 
Table 1. Presence of herpes simplex virus type 1 infection in different brain regions of control and neuropathologically confirmed Alzheimer's disease patients segregated by apoE genotype.

\begin{tabular}{|c|c|c|c|c|c|c|}
\hline Brain Region & apoE $\varepsilon 4$ & HSV-1 & $\begin{array}{c}\text { Controls } \\
n=36\end{array}$ & $\begin{array}{l}\text { Alzheimer's Disease } \\
\qquad \mathrm{n}=74\end{array}$ & Odds Ratio (95\% CI) & $p$ value \\
\hline \multirow[t]{4}{*}{ Hippocampus } & negative & negative & 11 & 12 & reference & \\
\hline & negative & positive & 18 & 20 & $1.02(0.36-2.87)$ & 0.82 \\
\hline & positive & negative & 2 & 16 & $7.33(1.36-39.45)$ & 0.03 \\
\hline & positive & positive & 5 & 26 & $4.77(1.35-16.8)$ & 0.03 \\
\hline \multirow[t]{4}{*}{ Frontal Cortex } & negative & negative & 11 & 12 & reference & \\
\hline & negative & positive & 18 & 20 & $1.02(0.36-2.87)$ & 0.82 \\
\hline & positive & negative & 1 & 12 & $11.00(1.22-99.12)$ & 0.04 \\
\hline & positive & positive & 6 & 30 & $4.58(1.38-15.21)$ & 0.02 \\
\hline \multirow[t]{4}{*}{ Occipital Cortex } & negative & negative & 12 & 14 & reference & \\
\hline & negative & positive & 17 & 18 & $0.91(0.33-2.51)$ & 0.94 \\
\hline & positive & negative & 2 & 18 & $7.71(1.48-40.27)$ & 0.02 \\
\hline & positive & positive & 5 & 24 & $4.11(1.20-14.14)$ & 0.04 \\
\hline \multirow[t]{4}{*}{ Cerebellum } & negative & negative & 12 & 14 & reference & \\
\hline & negative & positive & 17 & 18 & $0.91(0.33-2.51)$ & 0.94 \\
\hline & positive & negative & 3 & 15 & $4.29(1.00-18.46)$ & 0.09 \\
\hline & positive & positive & 4 & 27 & $5.79(1.57-21.29)$ & 0.01 \\
\hline \multirow[t]{4}{*}{ Striatum } & negative & negative & 12 & 15 & reference & \\
\hline & negative & positive & 17 & 17 & $0.80(0.29-2.02)$ & 0.86 \\
\hline & positive & negative & 3 & 16 & $4.27(1.00-18.16)$ & 0.09 \\
\hline & positive & positive & 4 & 26 & $5.20(1.42-19.04)$ & 0.02 \\
\hline \multirow{4}{*}{$\begin{array}{l}\text { HSV }-1 \text { positivity in any } \\
\text { one of the five brain } \\
\text { regions }\end{array}$} & negative & negative & 9 & 11 & reference & \\
\hline & negative & positive & 20 & 21 & $0.86(0.29-2.51)$ & 0.99 \\
\hline & positive & negative & 1 & 9 & $7.36(0.78-69.62)$ & 0.13 \\
\hline & positive & positive & 6 & 33 & $4.50(1.30-15.52)$ & 0.03 \\
\hline
\end{tabular}

5 minutes at $97^{\circ} \mathrm{C}$ and 35 cycles each of 60 seconds at $97^{\circ} \mathrm{C}, 60$ seconds at $55^{\circ} \mathrm{C}$, followed by an additional extension of two minutes at $72^{\circ} \mathrm{C}$. PCR products were separated by $3 \%$ agarose gel (Pharmacia Biotech, Uppsala, Sweden) electrophoresis. Gels were stained with ethidium bromide (Pharmacia Biotech), photographed under UV light, and dried under vacuum at $70^{\circ} \mathrm{C}$ in a BioRad (Richmond, CA) gel dryer. Dried gels were then exposed to Kodak (Rochester, NY) XROMAT films. Autoradiographs were analyzed for the presence of the specific HSV-1 glycoprotein D DNA fragment by densitometry using an MCID system (St. Catherines, ON). ApoE genotype was determined using allele specific primers of purified brain DNA (32). Statistical comparisons were performed using $\chi^{2}$ analysis with Yates continuity correction with GraphPad software (San Diego, CA).

\section{RESULTS}

Table 1 describes HSV-1 DNA presence in control and AD brains by CNS area and by apoE genotype. The data demonstrate that the odds ratio (OR) for HSV-1 positivity in $\mathrm{AD}$ subjects is not increased relative to controls ( $p=0.82$ to 0.99 ). This holds true for all five of the brain regions examined as well as for the pooled data when any one of the five regions is considered positive. These data indicate that HSV-1 alone is not a risk factor for AD.
As expected, the apoE $\varepsilon 4$ allele frequency was much higher in neuropathologically confirmed AD patients than in controls. The overall OR for the $\varepsilon 4$ allele was 7.36 relative to the control group. This OR, although it did not reach significant levels due to low numbers in the HSV-1 negative group (80 of 120 patients were HSV-1 positive), is in agreement with the majority of previous studies linking apoE with sporadic late-onset AD (12). Furthermore, a significant correlation is obtained by pooling the HSV-1 negative and positive patients together and re-analyzing for only the apoE effect $(\mathrm{OR}=5.44 ; 95 \% \mathrm{CI}=2.11-13.99 ; p=0.0005)$. Therefore, the data confirm that the $\varepsilon 4$ allele of apoE is a significant risk factor for AD.

To determine if a synergy exists (for risk of AD) between the presence of HSV-1 DNA in brain and the $\varepsilon 4$ allele of apoE, odds ratios for positivity of both markers in the $\mathrm{AD}$ and control populations were calculated. No significant difference was found overall (when considering positivity for HSV-1 in any one of the five brain regions) between the OR for the combined presence of an $\varepsilon 4$ allele of apoE and HSV-1 positivity compared to individuals carrying only an $\varepsilon 4$ allele $(\mathrm{OR}=0.61 ; 95 \% \mathrm{CI}=0.06-5.75 ; p=0.94)$. Therefore, the current data indicate that no synergy for risk associated with AD exists between the presence of HSV1 DNA in the brain and the $\varepsilon 4$ allele of apoE. 
Furthermore, the data indicate that regions most affected in $\mathrm{AD}$, such as the hippocampus, are not more susceptible to HSV-1 infection, either alone or in combination with the $\varepsilon 4$ allele of apoE. Thus, these data suggest that no synergy exists in regions most affected in AD.

\section{DISCUSSION}

Data from this relatively large post-mortem casecontrol study indicate that there is no $\mathrm{AD}$ neuropathology-like gradient related to HSV-1 in the brain. Itzhaki and colleagues reported that the combination of HSV-1 in brain and carriage of an $\varepsilon 4$ allele of apoE is a strong factor for AD (28). These results provocatively suggested that a synergy may exist between these two markers. In an abridged version of the results presented here, the current authors' demonstrated that a synergy between these two markers does not exist (29).

To further address this issue, the current study analyzed the data by specific brain region to determine if a particular brain region, such as those primarily affected in $\mathrm{AD}$, may be at greater risk of HSV-1 infection than other brain areas. If HSV-1 was linked directly in some manner to $\mathrm{AD}$, then a distinction in brain region may have elucidated this mechanism, since regions such as the hippocampus and frontal cortex are more affected in $\mathrm{AD}$ than the occipital cortex, cerebellum or striatum. The data show that HSV-1 infection is as prevalent in regions affected in $\mathrm{AD}$ (hippocampus and frontal cortex) as those which are less affected (occipital cortex, cerebellum and striatum). Therefore, these data do not support the hypothesis that HSV-1 correlates with AD pathology. Also, as has been previously reported (5), by examining specific brain regions or by pooling the data, the relative frequency of HSV-1 DNA is not more prevalent in $\mathrm{AD}$ than in the control population. Consequently, this study confirms HSV-1 alone is clearly not a risk factor for AD, and analysis of any of the brain regions examined would generate the same conclusion.

The data presented here contrast with those presented by Itzhaki et al. (28), which suggested that the combination of HSV-1 in brain and presence of an $\varepsilon 4$ allele of apoE was a strong risk factor for AD. The failing of that study may lie in the fact that the data did not produce a significant effect for the $\varepsilon 4$ allele of apoE with respect to $\mathrm{AD}$. The $\mathrm{OR}$ for possession of an $\varepsilon 4$ allele was reported to be 1.67 (28), while the current study reported an OR of 7.36. Meta-analysis of studies examining apoE $\varepsilon 4$ allele frequencies in $\mathrm{AD}$ has determined that the OR for $\varepsilon 4$ allele carriers is between 2.6 and 14.9, depending on the genotype and population studied (12). This discrepancy in the datasets most likely explains the different conclusions.

Since no synergy was found for all of the regions pooled, the current authors were also interested to determine if perhaps synergy between HSV-1 and the $\varepsilon 4$ allele of apoE was indicated in a particular brain region, since brain regions such as the hippocampus are affected earlier in AD than other brain areas. No synergy was determined in any of the five brain regions examined, including the hippocampus, frontal cortex, occipital cortex, cerebellum or striatum. This indicates that synergy between HSV-1 and apoE does not correlate with $\mathrm{AD}$ pathology.

It is also suspected that, although great care may have been taken to determine HSV-1 in their brain samples, a potential sampling bias appears to be present in the study of Itzhaki et al., since normally the apoE $\varepsilon 4$ allele frequency is increased two to three fold within large $\mathrm{AD}$ samples relative to control populations (12). In their study, Itzhaki et al. found a 10 -fold difference $(0.045$ vs 0.430 ) between their cases and controls, undoubtedly due to an unknown sampling bias. It is very likely, therefore, that the findings are simply a reflection of the $\varepsilon 4$ allele of apoE being a significant risk factor for $\mathrm{AD}$ combined with the high prevalence of HSV-1 in the general population. Other studies which have examined this phenomenon may also be plagued by insufficient sample size. Itabashi et al. (33) examined $46 \mathrm{AD}$ cases and determined in accord with Itzhaki et al. (28) (also $46 \mathrm{AD}$ cases) that synergy may be indicated between the two markers. Therefore, results from studies with low case numbers may provide provocative conclusions, although the risk exists that these findings will not be replicated by larger, more exhaustive studies. However, the AD cases used in the different studies may also be at various stages of the disease. Therefore, the possibility remains that cerebral HSV-1 reactivation is developmentally related to AD pathology, while not being present at the end-stage of the disease.

In conclusion, synergy between the $\varepsilon 4$ allele of apoE and HSV-1 in AD development remains a matter of debate, and additional studies would be beneficial. In an attempt to unravel potential analytical biases with a larger population sample, the current authors' observed no synergy between these two markers in AD. Clinical studies based on case populations followed from the onset of the symptoms should prove useful in resolving this shaded area of $\mathrm{AD}$ research.

\section{ACKNOWLEDGMENTS}

The authors thank Drs. Heiko Wiebusch and Keith Schappert for helpful comments.This work was supported by grants from the Laboratory for Disease Control (Canada), the American Alzheimer's Association and the Medical Research Council of Canada.

\section{REFERENCES}

1. Ball MJ. Limbic prediliction in Alzheimer dementia: is reactivated herpes virus involved? Canadian Journal of 
Neurological Sciences 9: 303-306; 1982.

2. Gautrin D, Gauthier S. Alzheimer's disease: environmental factors and etiologic hypotheses. Canadian Journal of Neurological Sciences 16: 375-387; 1989.

3. Puchhammer-Stockl E, Popow-Kraupp T, Heinz FX, et al. Establishment of PCR for the early diagnosis of herpes simplex encephalitis. Journal of Medical Virology 32: 77-82; 1990.

4. Takasu T, Furuta Y, Sato KC, et al. Detection of latent herpes simplex virus DNA and RNA in human geniculate ganglia by the polymerase chain reaction. Acta Oto-Laryngologica 112: 1004-1011; 1992.

5. Bertrand P, Guillaume D, Hellauer K, et al. Distribution of herpes simplex virus type 1 DNA in selected areas of normal and Alzheimer's disease brains: a PCR study. Neurodegeneration 2: 201-208; 1993.

6. Jorm AF, Korten AE, Henderson AS. The prevalence of dementia: a quantitative integration of the literature. Acta Psychiatrica Scandinavica 76: 465-479; 1987.

7. Corder EH, Saunders AM, Strittmatter WJ, et al. Gene dose of apolipoprotein E type 4 allele and the risk of Alzheimer's disease in late onset families. Science $261: 921-923 ; 1993$.

8. Utermann G, Langenbeck U, Beisiegel U, Weber W. Genetics of the apolipoprotein E system in man. American Journal of Human Genetics 32: 339-347; 1980.

9. Rebeck GW, Reiter JS, Strickland DK, Hyman BT. Apolipoprotein E in sporadic Alzheimer's disease: allelic variation and receptor interactions. Neuron 11: 575-580; 1993.

10. Poirier J, Davignon J, Bouthillier D, et al. Apolipoprotein E polymorphism and Alzheimer's disease. Lancet 342: 697-699; 1993.

11. Strittmatter WJ, Saunders AM, Schmechel DE, et al. Apolipoprotein E: high-avidity binding to $\beta$-amyloid and increased frequency of type 4 allele in late-onset familial Alzheimer disease. Proceedings of the National Academy of Sciences (USA) 90: 1977-1981; 1993.

12. Farrer LA, Cupples LA, Haines JL, et al. Effects of age, sex, and ethnicity on the association between apolipoprotein $\mathrm{E}$ genotype and Alzheimer disease. A meta-analysis. JAMA 278: 13491356; 1997.

13. Nathan BP, Bellosta S, Sanan DA, Weisgraber KH, Mahley RW, Pitas RE. Differential effects of apolipoproteins E3 and E4 on neuronal growth in vitro. Science 264: 850-852; 1994.

14. Nathan BP, Chang KC, Bellosta S, et al. The inhibitory effect of apolipoprotein E4 on neurite outgrowth is associated with microtubule depolymerization. Journal of Biological Chemistry 270: 19791-19799; 1995.

15. Holtzman DM, Pitas RE, Kilbridge J, et al. Low density lipoprotein receptor-related protein mediates apolipoprotein Edependent neurite outgrowth in a central nervous systemderived cell line. Proceedings of the National Academy of Science (USA) 92: 9480-9484; 1995.

16. Strittmatter WJ, Weisgraber KH, Huang DY, et al. Binding of human apolipoprotein $\mathrm{E}$ to synthetic amyloid $\beta$ peptide: isoformspecific effects and implications for late-onset Alzheimer disease. Proceedings of the National Academy of Sciences
(USA) 90: 8098-8102; 1993.

17. LaDu MJ, Falduto MT, Manelli AM, et al. Isoform-specific binding of apolipoprotein $\mathrm{E}$ to $\beta$-amyloid. Journal of Biological Chemistry 269: 23403-23406; 1994.

18. LaDu MJ, Pederson TM, Frail DE, et al. Purification of apolipoprotein $\mathrm{E}$ attenuates isoform-specific binding to $\beta$ amyloid. Journal of Biological Chemistry 270: 9039-9042; 1995.

19. Beffert U, Aumont N, Dea D, Lussier-Cacan S, Davignon J, Poirier J. $\beta$-amyloid peptides increase the binding and internalization of apolipoprotein $\mathrm{E}$ to hippocampal neurons. Journal of Neurochemistry 70: 1458-1466; 1998.

20. Strittmatter WJ, Saunders AM, Goedert M, et al. Isoformspecific interactions of apolipoprotein $\mathrm{E}$ with microtubuleassociated protein tau: implications for Alzheimer disease. Proceedings of the National Academy of Sciences (USA) 91: 11183-11186; 1994.

21. Strittmatter WJ, Weisgraber KH, Goedert M, et al. Hypothesis: microtubule instability and paired helical filament formation in the Alzheimer disease brain are related to apolipoprotein $\mathrm{E}$ genotype. Experimental Neurology 125: 163-171; 1994.

22. Poirier J. Apolipoprotein E in animal models of CNS injury and in Alzheimer's disease. Trends in Neurosciences 17: 525-530; 1994.

23. Poirier J, Delisle M-C, Quirion R, et al. Apolipoprotein E4 allele as a predictor of cholinergic deficits and treatment outcome in Alzheimer's disease. Proceedings of the National Academy of Sciences (USA) 92: 12260-12264; 1995.

24. Beffert U, Danik M, Krzywkowski P, et al. The neurobiology of apolipoproteins and their receptors in the CNS and Alzheimer's disease. Brain Research Reviews 27: 119-142; 1998.

25. Hyman BT, Hedley-Whyte ET, Rebeck GW, et al. Apolipoprotein E epsilon $4 / 4$ in a neuropathologically normal very elderly individual. Archives of Neurology 53: 215-215; 1996.

26. Rebeck GW, Perls TT, West HL, et al. Reduced apolipoprotein $\varepsilon 4$ allele frequency in the oldest old Alzheimer's patients and cognitively normal individuals. Neurology 44: 1513-1516; 1994.

27. Sobel E, Louhija J, Sulkava R, et al. Lack of association of apolipoprotein E allele epsilon 4 with late-onset Alzheimer's disease among Finnish centenarians. Neurology 45: 903-907; 1995.

28. Itzhaki RF, Lin WR, Shang DH, et al. Herpes simplex virus type 1 in brain and risk of Alzheimer's disease. Lancet 349: 241-244; 1997.

29. Beffert U, Bertrand P, Champagne D, et al. HSV-1 in brain and risk of Alzheimer's disease. Lancet 351: 1330-1331; 1998.

30. Khachaturian ZS. Diagnosis of Alzheimer's disease. Archives of Neurology 42: 1097-1105; 1985.

31. Lasky LA, Dowbenko DJ. DNA sequence of the type-common glycoprotein D genes herpes simplex virus type 1 and 2 . DNA 3: 23-29; 1984.

32. Nalbantoglu J, Gilfix BM, Bertrand P, et al. Predictive value of apolipoprotein E genotyping in Alzheimer's disease: results of an autopsy series and an analysis of several combined studies. Annals of Neurology 36: 889-895; 1994.

33. Itabashi $\mathrm{S}$, Arai $\mathrm{H}$, Matsui $\mathrm{T}$, et al. Herpes simplex virus and risk of Alzheimer's disease. Lancet 349: 1102-1102; 1997.

Uwe Beffert earned his B.Sc. in biochemistry at Concordia University (Montreal, Quebec, Canada) in 1991. He is currently completing his Ph.D. from the Department of Neurology and Neurosurgery, McGill University (Montreal, Quebec, Canada) and will shortly be pursuing post-doctoral training in the Department of Molecular Genetics, University of Texas Southwestern Medical Center at Dallas (Texas, USA). 